1147 INTRACRANIAL PRESSURE IN REYE'S SYNDROME. Milo $D$. Hilty, Earl S. Sherard, Carolyn A. Romshe, Hugo J. McClung and Ralph E. Haynes. Ohio state Univ. CoTlege of Medicine, Children's Hospital, Dept. of Pediatrics, Cols.,Ohio. During the past 3 years the intracranial pressure (ICP) of 17 children with Reye's Syndrome(RS) has been monitored. The epidural monitor was placed in patients whose level of coma was III or ICP was measured on 15 patients on admission to the hospital. The pressure was $200 \mathrm{~mm} \mathrm{H} \mathrm{H}_{2} \mathrm{O}$ or less in 7 patients and $300 \mathrm{~mm} \mathrm{H}_{2} \mathrm{O}$ or less in 13 patients. In survivors maximum ICP was recorded at 8-24 hours after admission and correlated with the level of coma. An ICP of 400-800 mm $\mathrm{H}_{2} \mathrm{O}$ was associated with coma level of IV or deeper. In one child the ICP was greater than $1300 \mathrm{~mm} \mathrm{H}_{2} \mathrm{O}$. In 8 patients abrupt increases in ICP to $700 \mathrm{~mm} \mathrm{H}_{2} \mathrm{O}$ or greater occurred and preceded any clinical evidence of increasing ICP. These episodes lasted 20-30 minutes, and were treated with hyperventilation and/or mannitol. In 4 patients these episodes were repetitive, being separated by intervals of 2-12 hours. Most of our patients were admitted to the hospital during the early hours of their illness and were in Stage II or III coma. During this phase, the level of consciousness does not appear to be directly related to the ICP, however if the level of coma deepens during the next 24 hours after admission the ICP correlates with the stage of coma. Continuous ICP monitoring is essential for the optimal management of intracranial hypertension associated with RS and serves as an objective criteria for the administration of hyperosmolar agents in patients with coma Stage III or deeper. EFFECTS OF ELEVATED BILIRUBIN AND PHOTOTHERAPY ON IN1148 cinctnaty. erland, Univ. of Cint1., Col. of Med., Dept. of Ped., in fants. The Graham/Rosenblith Neonatal Assessment Scales were administered at 12 hour intervals to infants throughout their hospital stay. Group I $(n-12)$ had B111 $\leq 7 m g \%$. Group II $(n=18)$ had $B 111>10 \mathrm{mg} \%$ without $R x$. Group III had $B 111>10 \mathrm{mg} \%$ and were treated from $\overline{7}-85 \mathrm{hrs}(\bar{X}=39.6+6.5 \mathrm{hrs})$. B111 for Group III infants dropped from $14.4+.3 \mathrm{mg}$ to $10.1+.6 \mathrm{mg} \%$ post-Rx $(t=6.68, p<.01)$. By post hoc from 14.4 hr. $3 \mathrm{ngz}$ to $10.1 \pm 6 m 8 \%$ post analyses the groups ancared simtar in all hire, ant, and time delivery characteristics evaluated. Age, amount fed, and time since feeding were significantly correlated with specific measures. Variance due to these uncontrolled factors were statist1cally removed for evaluation of differences between groups. Further adfustments were made for B111 to 1 solate affects of

therapy treatment from those related to billrubin alone.

Scores on general maturation items, muscle tension scores, $11 \mathrm{mb}$ extension responses, and strength of cry were lowered by B111 and apparently not further affected by Rx. Prolonged limb elevation increased in response to passive movement, and pitch of cry was lowered for treated Infants and were not related to Bill.
Severity of trembling was increased both by B1ll and by Rx. Location of trembling responses and the types of stimuli eliciting trembling were Increased by B1ll and perhaps also by pre-delivery medication. Infant neuro-psychological behavior is significantly meffected by hyperbilirubinemia and by treatment with phototherapy. 1149 ALTERATIONS IN THE FUNCTIONAL ORGANIZATION OF THE TO MONOCULAR VISUAL DEPRIVATION. Charles Kennedy, Michael Des Rosiers, Osamu Sakurada and Louis Sokoloff. Georgetown University School of Medicine, Department of Pediatrics. washington, D.C. and National Institute of Mental Health, Laboratory of Cerebral Metabolism, Bethesda, Md.

ingle cell recordings and anatomic studies of striate cortex in the monkey have shown that prolonged monocular visual deprivation begun in the second or third week of life results in alterations ir. cortical development. Specifically, the ocular dominance columns of the intact eye enlarge at the expense of those of the deprived eye (Hubel, D.H, et al 1976). We wished to learn of the deprived eye (Hubel, D.H. et al 1976). We wished to learn applied the $(14-C)$ deoxyglucose autoradiographic method for measurement of local glucose utilization. This technique, devised in our laboratory, delineates the relative metabolic rates (and hence levels of functional activity) in the cortical layers and other cerebral structures. By patching one eye just before the experimental procedure we could demonstrate the ocular dominance columns in the newborn monkey. An animal which had had the lids of one eye sutured closed at birth was studied at three months of age. Autoradiographs of the striate cortex which depicted layer four very clearly showed it to be free of regular interruption or other evidence of the ocular dominance columns. In comparable study of a mature monkey normal columns were found. We conclude that in the neonate plasticity permits the columns innervated by the deprived eye to be functionally displaced by those of the intact eye.
THE FFFECT OF BIRTH ASPHYYIA ON THE ETIOLOGY OF IN1150 TRAVENTRICILAR HFMORRHAGF (IVH). John D. Kenny, Joseph A. Garcia-Prats, James L. Hilliard, Anthony J.S. Corbet, Arnold Hedicine, Houston.

To assess the effect of birth asphyxia on the development of IVH, arterial blood was obtained from a clamped segment of umbil ical cord at birth from 60 premature infants of 26-36 weeks gestational age $(\mathrm{GA})$ and analyzed for $\left[\mathrm{H}^{+}+\mathrm{W}, \mathrm{pCO}_{2}\right.$, standard bicarbonate (SB), and blood lactic acid (BL). IVH was diagnosed in 16 infants by sudden clinical deterioration, hemorrhagic CSF and typical neurologic signs. 15 of these died and autopsies were obtained on 10 which confirmed the diagnosis of IVH. Infants with IVH were less mature (IVH 29.3 weeks $\pm 0.4 \mathrm{SF}$, no IVH 32.4 weeks $+0.3 \mathrm{SE}, \mathrm{p}<0.001$ ), had lower one minute Apgar scores (IVH 2.1 , no IVH 5.2, p $<0.001$ ), and had a higher incidence of HMD (IVH 12/16, no IVH $10 / 44, p<0.001)$. No differences were seen in any acidbase parameter except for $S B$ which is related to the positive correlation between $S B$ and $G A(r=0.35, p<0.025)$.

$\begin{array}{lllll}\text { Mean } \pm \mathrm{SE} & {\left[\mathrm{H}^{+}\right] \mathrm{nM} / \mathrm{L}} & \mathrm{SB} \mathrm{mM} / \mathrm{L} & \mathrm{pCO}_{2} \mathrm{~mm} \mathrm{Hg} & \mathrm{BL} \mathrm{mM} / \mathrm{L} \\ \text { IVH } & 71.3 \pm 5.8 & 13.0 \pm 0.9 & 42.2 \pm 3.6 & 4.5 \pm 0.5 \\ \text { no IVH } & 63.8 \pm 2.2 & 15.9 \pm 0.5 & 41.5 \pm 1.4 & 4.0+0.3 \\ \text { p } & >0.2 & <0.01 & >0.8 & >0 . \overline{3}\end{array}$

We conclude that birth asphyxia does not occur more frequently in premature infants who subsequently develop IVH and that the decreased Apgar score in infants with IVH is related to their immaturity and higher incidence of HMD.

BRAIN LEAD LEVELS IN HEMORRHAGIC LEAD ENCEPHALOPATHY 1151 Joseph A.Kochen and Y1gal Greener, Albert Einstein Coll. Lead $(\mathrm{Pb})$ encephalopathy in the newborn rat is characterized by hemorrhage restricted to the cerebellum. Th1s was produced by giving 7 day old rats $0.5 \mathrm{ml} 1 \% 210 \mathrm{~Pb}-a c e t a t e$ by gastric tube dally $x$ 7. This resulted on day 14 in significantly higher $\mathrm{Pb}$ levels in the cerebellum than cerebrum $(10.1 \pm 4.0$ vs $5.0 \pm 1.2 \mathrm{Hg}$ $\mathrm{Pb} / \mathrm{gm})(\mathrm{M} \pm \mathrm{SD})$. Since red blood cells (RBC) contain much $\mathrm{Pb}, 1 \mathrm{t}$ was unclear whether the higher cerebellar levels reflected extravasation of RBC or increased capillary permeability to $\mathrm{Pb}$. This was resolved by labelling RBC by prior injection of $59 \mathrm{Fe}$ and quantitation of RBC trapping in brsin. Pb administration resulted in a significant increase in RBC sequestration in the cerebellum (from control levels of $10.1 \pm 1.1$ to $49.3 \pm 27.8 \mu 1 \mathrm{RBC} / \mathrm{gm}$ ), but 11ttle change in the cerebrum (from $9.5 \pm 1.0$ to $10.9 \pm 1.1 \mu 1 / \mathrm{gm}$. This increased retention of RBC accounted for $62.7 \pm 24.2 \%$ of the $\mathrm{Pb}$ in the cerebellum and $29.1 \pm 7.9 \%$ in the cerebrum. The remaining $\mathrm{Pb}$ represented the actual concentration of $\mathrm{Pb}$ in cerebellum $(3.6 \pm 2.4 \mu \mathrm{g} / \mathrm{gm})$ and cerebrum $(3.6 \pm 0.9 \mu \mathrm{g} / \mathrm{gm})$. Thus, the level of $\mathrm{Pb}$ in hemorrhagic regions of the brain proved to be identical to that in unaffected regions. The restriction of hemorrhage to the cerebellum despite the uniform distribution of $\mathrm{Pb}$ in the brain indicates that the cerebellar capillaries are particularly vulnerable to the toxic effects of $\mathrm{Pb}$.

\section{VISUALLY-ELICITED FINGER EXTENSION IN INFANTS: REFLEX} 1152 OR REACHING? IrIs MCGulre \& Gerald Turkewitz (Spon. Department of Pedlatrics, Bronx, New York

Arm and finger movements commonly observed in young infants may be neither responses to internal stimuli, nor attempts to "reach for" objects, but reflex-like responses to stimulation from objects. Schnelrla's Approach-WI thdrawal Theory proposes that at early stages of development in all animals, low Intens Ities of stimulation evoke approach responses and high intensitles evoke withdraw 1. This hypothesis was tested in 26 human infants by observing their finger responses to a cone that varied in in tensity. It was near or far, large or small, bright or dim, with elght combinations from low (far-small-dim) to high (near-iargebright) intensity. Flnger movements (flexlon or extenslon) were recorded and ratios of extensions/flexions + extensions computed. There were significant age, intensity, and age $x$ intensity effects with younger infants' (10-15 weeks) responses clearly related to intensity, while older infants' (20-25 weeks) responses were not. Younger infants made more extensions (approach) to low intensity st Imuli, and more flexions (withdrawal) to high intensity stimuli, their extension ratios following an inverse intensity gradient. Such reflex-like responses in very young infants may contribute to the development of reaching by bringing the hands and other objects into the visual fleld so that intersensory integration can occur. The development of reaching may thus be facilitated by presenting infants stimuli that effectively eliclt approach responses. 